\section{Mães HIV positivo e a não-amamentação}

\section{HIV positive mothers and the not breastfeeding}

Cirlei Célia Gomes Sanchez Moreno 1

Marina Ferreira Rea 2

Elvira Ventura Filipe 3

1 Programa Bolsa-Auxílio ao Desempregado. Secretaria de Relações do Trabalho. Prefeitura do Município de Guarulhos. Rua Antonio Iervolino, 225. Vila Augusta. Guarulhos, SP, Brasil. CEP: 07.021-160 E-mail: cipsi18@ hotmail.com 2 Núcleo de Saúde Materno Infantil. Instituto de Saúde. Secretaria de Estado da Saúde. São Paulo, SP, Brasil.

3 Centro de Referência e Treinamento Doenças Sexualmente Transmissíveis e Síndrome da Imunodeficiência Adquirida. Divisão de Prevenção. São Paulo, SP, Brasil.

\section{Abstract}

Objectives: understand the implications of preventing mothers from breastfeeding and the reasons they follow recommendations not to breastfeed.

Methods: a qualitative method where social phenomenology was used as a theoretical and methodological reference. The group consisted of 17 mothers in an outpatient pediatrics clinic. Some of the mothers were HIV positive; some had a non determined infectuous status. The content analysis method was used.

Results: being prevented to breastfeed made mothers feel unfulfilled and belittled. Avoiding breastfeeding implies changing the mother and baby relationship. Prejudice and discrimination are present. Choosing not to breastfeed is a way to protect babies from HIV contamination avoiding guilt and winning Society's forgiveness.

Conclusions: results indicate that "breastfeeding prohibition"- displayed by breasts in dressing - is considered painful and harsh. It involves the wish of maintaining the baby healthy based more on social, cultural and emotional issues than in biological ones. It seems to indicate that healthcare professionals ignore mothers'feelings when these mothers are faced with the problem of not being able to breastfeed.

Key words Breast feeding, Women's health, HIV, Disease transmission, vertical, Psychological phenomena and processes, Qualitative research

\section{Resumo}

Objetivos: compreender o significado da experiência de não amamentar e as razões que levam as mães a seguirem tal recomendação.

Métodos: estudo qualitativo onde a fenomenologia social foi tomada como referencial teórico-metodológico. O grupo estudado consistiu em 17 mães de um ambulatório infantil. Algumas mães eram HIV positivo, algumas apresentavam um status de infecção não determinado. Utilizou-se o método de análise de conteúdo.

Resultados: entre as razões destacadas para não amamentar, foram identificados sentimentos de não se considerarem completas e valorizadas como mães. Vivenciar a não-amamentação implica na reestruturação da relação mães/bebê, traz preconceitos e discriminação. A não-amamentação é uma forma de impedir a infecção do bebê pelo HIV e uma forma de eximir-se de culpa, obtendo assim perdão da sociedade.

Conclusões: os resultados mostram que "não amamentar" - conduta indentificada pelo enfaixamento dos seios - é considerado doloroso e punitivo. Envolve o desejo de manter sadio o bebê e, mais do que aspectos biológicos, implica em questões sociais, culturais $e$ emocionais. Parecem indicar ainda falta de atenção dos profissionais da área da saúde ao sentimento das mães, quando essas enfrentam o dilema da não-amamentação.

Palavras-chave Aleitamento materno, Saúde da mulher, HIV, Transmissão vertical de doença, Fenômenos e processos psicológicos, Pesquisa qualitativa 


\section{Introdução}

O crescimento da epidemia da AIDS entre as mulheres levou, conseqüentemente, ao aumento do número de casos em crianças, sendo a maioria devida à transmissão vertical,1 na qual o HIV pode ser transmitido da mãe para o filho durante a gestação, durante o parto e pela amamentação. ${ }^{2}$

Em países desenvolvidos, a ampla implementação de intervenções para a redução da transmissão vertical do HIV, principalmente a administração de anti-retrovirais, a cesariana eletiva e a substituição do leite materno, resultaram na redução significativa da incidência de casos de AIDS em crianças. ${ }^{3}$ Por outro lado a taxa de transmissão vertical do HIV, sem qualquer intervenção, situa-se em torno de $20 \% .4$

No Brasil, embora essas intervenções estejam disponíveis para toda a população de gestantes infectadas pelo HIV e seus filhos, há dificuldades da rede de saúde em prover diagnóstico laboratorial da infecção pelo HIV. A cobertura de mulheres testadas no pré-natal é insuficiente, principalmente nas populações mais vulneráveis, e a qualidade do pré-natal ainda está aquém do desejável. A administração de zidovudina injetável é realizada em menos de $50 \%$ dos partos do total de mulheres estimadas como infectadas pelo HIV.5

Apesar dessas dificuldades, nos últimos anos, a incidência de casos de AIDS em crianças vem decrescendo progressivamente no Brasil.5 Além disso, o país tem um programa de diagnóstico e tratamento gratuito e universal para o HIV/AIDS que recomenda a substituição da amamentação por leite artificial como uma das frentes de prevenção da infecção pelo HIV da mãe para o bebê - embora, no caso de mães saudáveis a amamentação seja amplamente incentivada. ${ }^{6}$

A imagem da amamentação, de alguma maneira, tem povoado o mundo das mulheres, enquanto símbolo representativo da maternidade, construído social e culturalmente ao longo dos tempos, paradoxalmente tido como determinação biológica da espécie. ${ }^{7}$ A amamentação não se esgota apenas em fatores biológicos, mas abrange dimensões construídas culturalmente, socialmente e historicamente. 8

Para as mulheres, a AIDS é uma doença que afeta diretamente a identidade social, sendo essa uma razão pela qual é em torno dos aspectos sociais e morais nela implicados que se estabelece uma identidade de mulher HIV positivo. ${ }^{9}$ É através do sofrimento imposto pelas restrições que a AIDS impõe às mulheres, que elas se tornam capazes de reconhecerem-se umas nas outras. Elas sabem avaliar as implicações de ter um filho doente sob o status de mãe, as sanções sociais a que estão submetidas pela não-amamentação, os conflitos desencadeados pela doença entre o cônjuge e os consangüíneos e as dificuldades de contornar todas essas situações. ${ }^{9}$

Para garantir seu status social, as mulheres portadoras do HIV precisam enfrentar, por exemplo, a condenação social suscitada por uma gestação. Além disso, devem enfrentar também a exigência por parte dos profissionais de saúde do uso de preservativo e, paralelamente, a recusa masculina em usá-lo, além das pressões sociais em favor da amamentação e a recomendação médica de não amamentar. 9

A orientação da World Health Organization (WHO) 10 sobre a alimentação infantil para bebês de mães HIV positivo é que elas suspendam a amamentação e utilizem os substitutos do leite materno quando forem aceitáveis, factíveis, acessíveis, seguros e sustentáveis; caso contrário a WHO recomenda a amamentação exclusiva durante os seis primeiros meses de vida do bebê. 10

No Brasil a recomendação é de que mães HIV positivo não amamentem seus filhos, nem doem leite para Bancos de Leite Humano (BLH); contra-indicase também o aleitamento materno cruzado (aleitamento por outra mulher), orienta-se a "secagem" do leite da lactente e disponibiliza-se gratuitamente a fórmula infantil durante os seis primeiros meses de vida de crianças expostas. 11

O presente trabalho objetivou estudar a vivência da não-amamentação de mães HIV positivo, e os aspectos sociais relacionados à orientação para não amamentar.

\section{Métodos}

Trata-se de um estudo qualitativo tendo como referencial teórico a fenomenologia social. A pesquisa fenomenológica procura introduzir um rigor não dependente da precisão numérica nos fenômenos não passíveis de serem estudados quantitativamente, tais como, angústia, ansiedade, medo, alegria, cólera, amor, tristeza, solidão etc. 12 Procura aproximar-se do fenômeno, de modo que não o paralisa ou o explica por meio de conceitos antecipados, de crenças ou afirmações sobre eles. ${ }^{13}$

Neste estudo, o referencial teórico-metodológico utilizado foi a fenomenologia sociológica de Schültz,14 que se fundamenta no indivíduo que vivencia a experiência. Essa abordagem permite captar a realidade social, situando as pessoas na 
atitude natural, portanto, em seu próprio mundo. 15

O estudo foi realizado em um Ambulatório de Saúde da Criança da Secretaria Municipal de Saúde de um município, na região metropolitana de São Paulo, no período de novembro de 2002 a agosto de 2003. O nome do município foi omitido por questões éticas, segundo compromisso assumido com o Conselho de Ética do Instituto de Saúde de São Paulo.

Esse município possui um local especializado para atenção à mulher HIV positivo (Estadual) e um para o acompanhamento dos bebês de mães soropositivas para o HIV (Municipal). Possui um banco de leite humano (BLH) localizado no Hospital Infantil do mesmo e dois postos de coleta de leite humano, ambos instalados sob a orientação do BLH em Hospitais Maternidades que atendem pelo Sistema Único de Saúde (SUS).

Para a coleta de dados foram realizadas entrevistas individuais semi-estruturadas, não diretivas, guiadas por questões orientadoras. A entrevista não diretiva ajuda a estabelecer o acordo entre as experiências organicistas, isto é, os comportamentos disponíveis à consciência e a representação adequada delas, permitindo a harmonia entre a experiência real e a construção que se faz dela, além de obter da pessoa entrevistada suas idéias, opiniões, maneira de sentir, de atuar, de pensar, sentimentos e informações de forma profunda em suas vivências. 16

Foi utilizado o critério de saturação para encerrar as entrevistas; isto é, quando, após as informações coletadas com certo número de mulheres, novas entrevistas passaram a apresentar uma quantidade de repetições em seu conteúdo. 17

Após a apresentação da pesquisadora e dos objetivos da pesquisa, iniciou-se a entrevista indagando se a entrevistada gostaria de contar sobre como soube que era HIV positivo. Neste momento se estabeleceu o envolvimento necessário para que houvesse empatia e confiança. Utilizou-se uma sala reservada que garantia o sigilo e conforto para a colaboradora. Foi solicitada, para cada uma das entrevistadas, autorização para gravar a entrevista, o que foi aceito. Mas, durante as primeiras entrevistas todas as entrevistadas apresentaram reações corporais negativas em relação ao processo de gravação. Olhavam o gravador com desconfiança e perguntavam se ninguém ouviria a fita e em alguns momentos foi solicitado seu desligamento. Diante da ocorrência desses fatos, dispensou-se a utilização do gravador, e os tópicos dos relatos foram anotados durante a entrevista e checados logo após, junto à entrevistada. Foram realizadas no máximo três entrevistas por dia, com duração média de uma a duas horas.
As perguntas eliciadoras da fala das entrevistadas foram:

- A senhora pode me falar como soube que tinha o HIV e como foi receber este diagnóstico?

- Em relação à amamentação. Qual a sua experiência?

- A senhora recebeu prescrição para secar o leite de seu peito?

- O que foi feito?

- Como foi para a senhora passar por este procedimento?

- Como a senhora se sentiu ao ser orientada a evitar dar o peito?

- Como está sendo alimentar seu bebê da forma que a senhora está fazendo neste momento?

- Acha que poderá levar adiante a decisão de evitar dar o peito?

Para a análise, foram realizadas a leitura e a releitura das falas para identificar categorias concretas entendidas como expressão e vivência das entrevistadas naquele momento.

Todos os aspectos significativos para a compreensão do fenômeno pesquisado foram destacados e numerados um a um em algarismos arábicos pela ordem seqüencial em que surgiram nos discursos, obtendo-se, assim, uma visão global do assunto. Teve-se o cuidado de mantê-los como foram expressos, extraindo desta forma as unidades de significado, que são discriminações percebidas nas descrições dos sujeitos, segundo atitude, disposição e perspectiva do pesquisador, e sempre focalizando o fenômeno em estudo. 12

Depois disso procedeu-se a redução fenomenológica na qual as unidades de significado foram reescritas na busca da clareza do relato, e as expressões cotidianas das entrevistadas foram transformadas em linguagem da pesquisadora. As transformações que ocorrem nesse momento realizam-se, basicamente, através de um procedimento de reflexão e de variação imaginativa das expressões dos sujeitos, obtendo as unidades de significados transformadas do relato. A variação imaginativa pode ser explicada como uma concentração cuidadosa d(a)o pesquisador(a) na descrição do sujeito, até encontrar nela um lugar e viver a situação imaginativamente, em todos os seus pormenores, ou seja, como ele pensa, analisa e julga a situação vivenciada. ${ }^{18} \mathrm{~A}$ seguir, partiu-se para a análise ideográfica, que é a análise da ideologia que permeia as descrições ingênuas do sujeito, referindo-se à representação de idéias por meio de símbolos e análise do aspecto individual de cada sujeito. 12

Procurou-se descrever como foi compreendido 
cada discurso, de forma a evidenciar a estrutura do fenômeno "ser mãe e não poder amamentar", a partir da individualidade de cada mulher. A compreensão surgiu das reflexões, que permitiram atribuir significados àquilo que se estava vendo e descobrindo. Essas etapas foram realizadas em cada entrevista, possibilitando ao final chegar à análise da ideologia que permeia as descrições individuais ingênuas das mulheres (análise ideográfica).

A passagem do individual para o geral corresponde à etapa da análise nomotética, onde começam a aflorar os aspectos mais comuns de todos os discursos, permitindo que o fenômeno se mostre, 12 obtendo-se assim as categorias analisadas.

Neste artigo são discutidas as seguintes categorias: "o diagnóstico": suas repercussões; "vulnerabilidades": a vulnerabilidade da mulher diante do HIV; o "lamento do corpo": os procedimentos para secar o leite; "o dilema da não-amamentação": a cobrança social, a alimentação do bebê, a vivência de não poder amamentar; "castigo/perdão - motivos para não amamentar": a culpabilização, expectativa em relação aos filhos, motivação para não amamentar; e "fatores sócio-culturais": crenças.

Para a realização do trabalho obteve-se aprovação ética do Comitê de Ética em Pesquisa do Instituto de Saúde sob número de Protocolo 020/03. Trata-se de um subprojeto da pesquisa "Avaliação da informação e da prática de aconselhamento de profissionais de saúde sobre alimentação de crianças expostas ao HIV Positivo das mães em São Paulo, Brasil" (ainda não publicada), que obteve aprovação do Comitê de Ética em Pesquisa do Instituto de Saúde sob o n. de Protocolo 010/02. Ambos seguem os princípios da Resolução 196/96 do Ministério da Saúde. A participação foi voluntária, mediante assinatura de Termo de Consentimento Livre e Esclarecido e explicação verbal sobre os objetivos da pesquisa, tanto para os sujeitos quanto para as instituições envolvidas - a Secretaria de Saúde e o Ambulatório de Saúde da Criança - com o compromisso de não revelar-se os nomes dos entrevistados e nem do município onde foi realizada a pesquisa.

\section{Resultados}

Na Tabela 1 são apresentadas algumas características das mulheres pesquisadas e de seus bebês. Os nomes aqui expostos são fictícios. O grupo foi constituído de 17 mulheres com idade entre 18 e 39 anos e com diagnóstico confirmado ou indeterminado para o HIV, mães de bebês com até três meses de vida. Metade do grupo foi composto por donas-de-casa e metade por mulheres que trabalhavam fora de casa. A maioria era multípara e metade tinha apenas o ensino fundamental incompleto.

\section{O momento do diagnóstico}

O momento do diagnóstico foi vivenciado pelas participantes como um momento de desespero e até com sentimento de morte iminente. Quando receberam a informação de serem HIV positivo, diversos sentimentos afloraram e tornaram-se conflituosos, principalmente quando o resultado foi indeterminado. Aparentemente, o encontro com outras mulheres HIV positivo pareceu amenizar a situação do diagnóstico e facilitou a aceitação e compreensão do processo do HIV, isto aliado à atenção acolhedora do profissional de saúde.

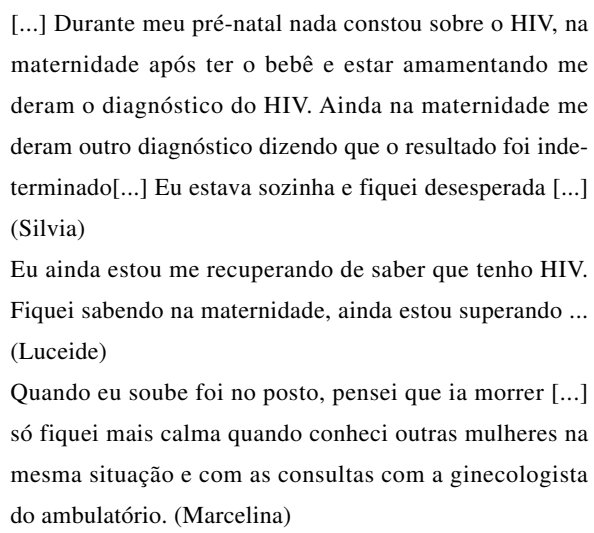

\section{Vulnerabilidades}

As participantes tinham idade entre 18 e 39 anos, em pleno período reprodutivo. Em seus relatos, observou-se que a questão da vulnerabilidade feminina em relação à infecção pelo HIV esteve presente.

Eu não sei como peguei o HIV, mas meu ex-namorado era usuário de drogas e por fim meu próprio marido que tem HIV. (Roseane)

[...] meu marido está aguardando meu resultado para depois fazer o próprio exame. (Stella)

Eu peguei HIV do meu marido, o meu marido já era portador e não me disse [...] talvez por medo. (Dielza)

Eu soube que tava com o vírus no pré-natal em outubro de 2002. O pai dela me passou isto (Joana)

Eu peguei a doença do pai da neném [...] (Rosicler)

O pai da minha filha não tem o vírus, eu me infectei por outro, um anterior [...] (Romualda)

O pai deste bebê não sabe que sou portadora, ele visita o João e eu tenho medo de contar e ele espalhar [...] (Marcelina) 
Tabela 1

Características gerais das entrevistadas.

\begin{tabular}{|c|c|c|c|c|c|c|}
\hline Nome da mãe* & Idade & Escolaridade completa ** & Ocupação & Paridade & Nome do bebê** & Idade \\
\hline Roseane & 28 & 5. ${ }^{a}$ série do Ensino Fundamental & Auxiliar de Produção & Multípara & Robson & 2 meses \\
\hline Silvia & 18 & 7. ${ }^{a}$ série do Ensino Fundamental & Do lar & Primípara & Giorgia & 17 dias \\
\hline Vera & 22 & 4. ${ }^{a}$ série do Ensino Fundamental & Catadora de Papelão & Multípara & Jorge & 2 meses \\
\hline Stella & 31 & 1. a série do Ensino Fundamental & Do lar & Multípara & Gilmar & 1 mês \\
\hline Dielza & 26 & 8. ${ }^{a}$ série do Ensino Fundamental & Do lar & Multípara & Geanderson & 2 meses \\
\hline Roselda & 30 & 2. ${ }^{a}$ série do Ensino Médio & Caixa & Multípara & Mariana & 3 meses \\
\hline Joana & 20 & 3. ${ }^{a}$ série do Ensino Médio & Auxiliar de acabamento & Primípara & Leidiene & 20 dias \\
\hline Mariza & 25 & 3. ${ }^{a}$ série do. Ensino Médio & Doméstica & Primípara & Milena & 12 dias \\
\hline Rosicler & 25 & 1. ${ }^{a}$ série do Ensino Médio & Doméstica & Multípara & Francisca & 24 dias \\
\hline Romualda & 30 & 2. ${ }^{a}$ série do Ensino Fundamental & Do lar & Primípara & Joelma & 19 dias \\
\hline Marcelina & 25 & 2. ${ }^{a}$ série do Ensino Médio & Desempregada & Multípara & João & 1 mês \\
\hline Mariana & 34 & 1. ${ }^{a}$ série do Ensino Médio & Costureira & Multípara & Juliano & 1 mês e 14 dias \\
\hline Graziela & 26 & 3. ${ }^{a}$ série do Ensino Médio & Do lar & Multípara & Gustavo & 2 meses \\
\hline Valdene & 24 & 5. ${ }^{a}$ série do Ensino Fundamental & Do lar & Multípara & Joana & 2 meses \\
\hline Lucinda & 36 & 3. ${ }^{a}$ série do Ensino Médio & Do lar & Multípara & Lenice & 1 mês e 10 dias \\
\hline
\end{tabular}

* Os nomes das mães são fictícios; ** Os nomes dos bebês são fictícios.

Meu marido não sabe e eu me separei dele [...] (Luceide)

Eu me infectei com outro parceiro e não com meu marido,

o pai de meus filhos não tem nada [...] (Graziela)

\section{O lamento do corpo}

Oito mães receberam prescrição para inibir a lactação com medidas não-hormonais (enfaixamento das mamas) e duas com medidas farmacológicas. Seis mulheres receberam os dois procedimentos como indicação, sendo que uma delas, no momento da entrevista, ainda estava lactando e uma não recebeu prescrição.

Uma dessas mulheres que recebeu as duas prescrições resolveu não comprar o medicamento ao sair da maternidade e ao chegar em casa retirou a faixa, pois tinha esperança de poder amamentar (resultado indeterminado); outra, em razão de não ter condições financeiras para comprar o medicamento, o tomou quando parentes lhe emprestaram dinheiro para comprar.

O método para inibição da lactação mais presente no relato das entrevistadas foi o de enfaixamento, não havendo em suas falas aspectos aparentemente emocionais ou físicos envolvendo o uso de medicamentos, exceto pela condição de rejeição de utilização do método ou por questões financeiras de não poder comprá-lo.

\begin{abstract}
Na maternidade o médico receitou medicamento, mas eu não tomei porque tenho esperança de amamentar minha filha. Também puseram faixa, mas eu tirei quando cheguei em casa. Estou tirando o leite com bombinha e jogando fora. (Joana)

No hospital me disseram para enfaixar o peito e o médico deu receita pra comprar remédio e secar o leite. Na farmácia disseram que aqueles comprimidinhos custavam $\mathrm{R} \$ 50,00$, não tive dinheiro pra comprar, pedi emprestado e tomei. Então eu usei sutiã apertado e tirei leite com a mão. (Marcelina)
\end{abstract}

A realização de procedimento para interromper a lactação através do enfaixamento foi caracterizada pela maioria das entrevistadas como violenta e lhes trouxe sensação de poda, de cerceamento, de "ir contra a natureza".

Estão presentes nos relatos intercorrências mamárias que provavelmente surgiram em razão do não-esvaziamento adequado das mamas antes do procedimento e durante o processo em que as mamas estiveram enfaixadas. Há relatos de dores, febres e ingurgitamento mamário, tornando a não-amamentação ainda mais penosa e punitiva, o que mostra inabilidade dos profissionais de saúde quanto ao manejo da lactação.

No hospital enfaixaram, passaram comprimido e eu comprei, foi mais de $\mathrm{R} \$ 60,00$. Em casa meu leite empedrou e 
eu tive febre. O médico passou dipirona e diclofenato.

(Dielza)

Fui enfaixada, acaba com a gente, é horrível, não agüentava de dor e não fiz em casa. Meu leite empedrou, imagina, empedrado e enfaixado, aconteceu na maternidade e lá não fizeram nada, foi em casa que eu fiz compressa quente e aos poucos foi cedendo. A enfermeira mandou eu tirar o leite do peito, mas minha mãe falou que não, porque ia aumentar [...] Então o pouco que eu tirei joguei fora. (Roselda)

Eu tive dor no peito, febre e meus peitos ficaram duros, não saía de debaixo do chuveiro. Passava pente e aí aliviava. O leite saía na água e ia para o ralo. (Rosicler)

O problema foi só quando eu cheguei em casa da maternidade, eu tive dor no peito, febre, meu peito encheu. Só aliviou quando eu fiz uma compressa quente e passei óleo. Também tirei leite e joguei fora. Meu peito foi enfaixado na maternidade, eu tive febre e me deram analgésico, aí eu fiquei sem respiração e me deram outro remédio, então eu melhorei. (Romualda)

Me enfaixaram, eu chorava de dor, machuca muito e, também passaram medicamento. (Romualda)

\section{O dilema da não-amamentação}

Para as participantes deste estudo a experiência da impossibilidade de amamentar foi penosa e emocionalmente desgastante.

Os curiosos me perguntam por que não estou amamentando, e eu digo que é porque eu tenho anemia. Me senti arrasada quando disseram que eu não podia dar o peito, eu estava amamentando ela na Maternidade e eles disseram que eu não podia porque eu tinha AIDS. Eu acho errado alimentar ela assim, sem leite materno. O leite materno é o melhor leite para a criança. Vou alimentar ela assim até sair o resultado do meu exame. (Silvia)

Eu me senti triste, não poder dar o peito é ruim. Acho ruim alimentar o Jorge assim, por mim queria dar leite do peito. (Vera)

[...] nem pude deixar ele tocar na mama. Não posso ter a sensação de dizer que ele mamou. Dá uma dor bem forte no peito. (Dielza)

Eu me sentia vazia, não falava no assunto. (Roselda)

Pra gente se sentir mãe tem que amamentar. Só agora eu começo a me sentir mãe dela. (Joana)

Quando me orientaram para não amamentar me senti triste, deu um desespero, chorei muito, dá uma tristeza. Eu acho ruim alimentar ela com outro leite, eu quero dar o peito. Ela fica procurando. (Mariza)

Senti como se eu não prestasse. Se meu corpo não pode oferecer pra ela nada de bom, então ele não presta. Me senti uma pessoa inútil. (Rosicler)

Quando eu soube que não poderia dar o peito foi um choque, chorei bastante, foi difícil pra mim, me senti triste, arrasada. Mas o ideal seria o leite de peito. Como não posso amamentar vai deste jeito mesmo [...] Quando cheguei em casa com o João sofri muita pressão. Muita gente veio conhecer ele e perguntavam porque eu não tava dando o peito, eu repeti a história várias vezes, que tive uma infecção de urina e estava com medicação forte e só podia amamentar depois de um mês. Agora digo pra todo mundo que o leite secou. (Marcelina)

Quando eu fui orientada a não dar o peito eu fiquei com um peso dentro do peito. Foi pior que o vírus, meu sonho era engravidar e poder amamentar. Acho legal alimentar o Carlos como estou fazendo, mas o leite materno é melhor, mas infelizmente não posso dar e a gente tem de dar este. (Luceide)

As pessoas perguntam por que você não está dando o peito e eu me sinto constrangida em ter que mentir. Hoje em dia estou acostumada, mas é ruim quando as pessoas perguntam por que não estou amamentando e a gente tem de inventar desculpas. Mesmo sem ter experimentado dar de mamar, sei que o contato é diferente do da mamadeira, ainda hoje tenho dificuldade em lidar com isso. Quando me disseram para não dar o peito, eu me senti um nada. Você espera aquele contato e a mamadeira é diferente. (Graziela)

Me senti muito mal e arrasada quando soube que não podia amamentar. Foi como se não tivesse mais valor como mãe para a Joana. (Valdene)

\section{Castigo/Perdão - Motivos para não amamentar}

Os relatos, experiências e vivências foram similares e demonstram que o típico da ação destas mulheres é o de proteger o outro em detrimento de si, embora também proteger o outro em benefício de si mesma. Isto é, quando uma mulher diz que quer proteger o filho da doença, ela quer proteger a si mesma, de forma a ter uma chance de ser perdoada e aceita pela sociedade, poderá entender que ela fez de tudo para poupar seu bebê da infecção. Não amamentar representa essa possibilidade. Diante de uma situação limite, o típico da ação vivida pode mostrar que o cuidar do outro se mistura com o cuidar de si.

\footnotetext{
Eu só quero proteger ele. Este bebê foi planejado [...] se ele não resistir só poderá ser castigo (pausa) [...] pensei em dar o peito para ele, mas fiquei com medo dele ficar doente e não dei, até porque eu dei para a minha filha que morreu e acho que tinha o HIV. Eu vou levar a decisão de não amamentar até porque meu leite secou. Eu só quero proteger ele. (Roseane)

... não sabia o que fazer, meu bebê mamou, mas eu acho que eu não tenho nada [....]. (Silvia)
} 
Ela me disse se eu estava querendo me matar [...] por quê vai matar o bebê e a si mesma ao pensar no que fez no futuro [...] mas tenho que proteger o Jorge, esta é minha preocupação principal. (Vera)

Senti vontade, por duas vezes senti vontade de dar o peito, ainda tenho leite, mas sei que não darei para o Carlos. (Luceide)

Me senti arrasada quando soube que não podia amamentar mas como era para o bem do Juliano eu fiquei tranqüila, mas o leite materno faz falta para a criança. (Mariana).

\section{Fatores sócio-culturais}

As participantes pareceram ter ouvido mitos sobre o leite materno, mitos esses presentes em suas memórias. É possível que a vivência da não-amamentação tenha trazido à tona conhecimentos adormecidos no inconsciente.

Esses mitos devem ser considerados em relação à força do simbolismo e implicação na decisão da mulher amamentar ou não.

Joguei no muro, dei para as formigas, joguei na terra, no pé de hortelã, onde falavam que secava, mas não adianta. (Joana)

Na maternidade o médico receitou medicamento, mas eu não tomei porque tenho esperança de amamentar minha filha. Também puseram faixa, mas eu tirei quando cheguei em casa. Estou tirando o leite com bombinha e jogando fora. Se as formigas lamberem meu leite, caso ele tenha caído no chão, ele vai secar?! (Mariza)

Embora que ela está engordando, acho que não está sustentando. (Rosicler)

Então eu usei sutiã apertado e tirei leite com a mão. Eu tirava e jogava fora no quintal, dizem que se você joga leite na terra ele seca, mas até agora [...] não. (Marcelina) Eu acho que ele está sempre com fome, toda hora ele chora. (Mariana)

\section{Discussão}

Como em outras pesquisas realizadas com mulheres HIV positivo, em que a maioria é infectada por parceiros fixos, 9 as participantes deste estudo também foram infectadas por seus maridos ou parceiros fixos, revelando a grande vulnerabilidade feminina ao HIV. Segundo Parker, ${ }^{19}$ sem que haja uma transformação das relações desiguais de poder de gênero que existe em toda sociedade, as mulheres do mundo inteiro continuarão a ser alvos preferenciais da própria insegurança. $O$ conceito de vulnerabilidade permite entender plenamente como questões relacionadas à desigualdade, estigma, discriminação e violência, dentre outras, aceleram a disseminação da epidemia de AIDS e quais indivíduos e grupos estão em situação de maior vulnerabilidade. Dentre eles, as mulheres.

As relações historicamente construídas de desigualdade entre os sexos, que colocam as mulheres em situação de vulnerabilidade, evidenciam a importância de incorporar às políticas públicas marcos conceituais que possam ser elucidativos no trabalho de prevenção ao HIV/Aids, como o conceito de gênero. ${ }^{20}$

Na nossa sociedade a importância da amamentação foi incorporada, sendo comum questionar-se a mãe de um recém-nascido se ele é amamentado. Para as participantes deste estudo não foi diferente. A cobrança social as coloca em situações constrangedoras e elas criam desculpas socialmente aceitas para justificar a não-amamentação. Nesse sentido, seria importante que o profissional de saúde, atento às recomendações nacionais, subsidiasse a mulher com argumentos relacionados à saúde, para que as mulheres portadoras do HIV pudessem explicar o fato de não amamentar de maneira mais plausível.5

Para Schultz, 14 o significado que se dá às vivências do outro não pode ser exatamente o mesmo que a própria pessoa dá ao interpretá-las. Na intersubjetividade dessas mulheres, "os outros" são elementos da situação que elas vivenciam, assim como elas são elementos deles. Isso não anula a história subjetiva de cada uma.

Verificou-se, pelo discurso das mulheres, que a experiência da impossibilidade de amamentar foi penosa e emocionalmente desgastante.

A não-amamentação (como a amamentação) envolve riscos e benefícios, 21 e para essas mulheres foi de certa forma um atestado de perdão, uma possibilidade de dar seguimento à vida, uma forma de se sentirem parte do processo ou totalmente afastadas do processo de decisão sobre a alimentação do filho.

Schültz 22 denomina como bagagem de conhecimentos disponíveis, uma estrutura sedimentada das experiências subjetivas prévias do indivíduo, adquiridas ao longo de sua vida por meio de experiências vivenciadas ou que a ele foram comunicadas por outras pessoas.

O diagnóstico de infecção pelo HIV é um processo que ocasiona importante impacto na vida das pessoas. É uma experiência de considerável intensidade emocional. 23

Segundo Santos, 24 a vivência do enfaixamento das mamas desencadeia uma imagem do corpo centralizado na mama, que afeta a mulher/mãe nas 
suas dimensões física, psíquica, social e cultural, estando intimamente inter-relacionadas, retratando o elevado nível de rejeição e repúdio expresso corporeamente pela maior parte das mulheres entrevistadas por esse autor. $\mathrm{O}$ corpo que recebe intervenção através de procedimentos para secagem do leite denota significados, e à medida que os significados vividos individualmente são contextualizados na relação intersubjetiva, vai se configurando uma relação social. 24

Os resultados do presente estudo sugerem que o uso de enfaixamento como processo de inibição da lactação é sentido como punidor e doloroso. O profissional de saúde que interage com a mulher HIV positivo ao diagnosticar ou realizar procedimentos para secar o leite, deve colocar-se imaginativamente no lugar da mulher, pois só assim terá o cuidado necessário para com o corpo do outro, respeitando seus limites e preparado para dialogar e informar.

Santos 24 procurou compreender o significado da amamentação para o ser-mulher/mãe HIV positivo e verificou o elevado nível de rejeição e repúdio expresso corporeamente pela maior parte das mulheres/mães entrevistadas acerca do procedimento adotado como rotina pelos serviços de saúde, no caso, o enfaixamento. Elas alegaram sensações no plano físico, emocional e moral, que incluiu: sentirse doente, diferente, mal-estar, revolta, angústia, impotência, perda de identidade feminina e materna, perda simbólica da mama, sufocamento, prurido, alergia, desconforto físico, constrangimento, sentimento de inferioridade, dor, tristeza, discriminação e humilhação. No presente estudo verificou-se que as sensações e sentimentos das entrevistadas foram semelhantes àquelas relatadas por Santos. 24

Na prática clínica, a supressão da lactação está restrita a um pequeno número de situações individuais e, dentre elas, pelas normas brasileiras, a presença da infecção materna pelo vírus HIV, devido ao comprovado aumento da transmissão do vírus pelo leite materno. ${ }^{1}$

A supressão da lactação baseia-se em medidas não-hormonais ou clínicas e medidas farmacológicas. O método não-hormonal é relatado como o mais "simples" e consiste em comprimir "confortavelmente" as mamas (enfaixamento), aplicação de bolsa de gelo ou compressas frias (por um período menor ou igual a 10 minutos) e administração de analgésico. ${ }^{1}$

O enfaixamento é um procedimento adotado como rotina pelos serviços de saúde, conforme recomendação preconizada pelo Ministério da Saúde 25 e deve sempre estar baseado no consentimento livre e esclarecido das puérperas. 24
Atualmente, nas situações em que está indicado a supressão da lactação, como no caso das mulheres/mães HIV positivo, o método de eleição recomendado pelo UNICEF (United Nations International Children' Emergency Fund) 26 é o fisiológico, pois os métodos farmacológicos de supressão da lactação estão contra-indicados devido a efeitos colaterais.

Os resultados do presente estudo apontam para a necessidade de se rever a prática do enfaixamento, pois outros aspectos não-biológicos devem ser considerados. O esclarecimento da mulher sobre tal procedimento é importante.

Knauth ${ }^{9}$ observou que as mulheres HIV positivo por ele entrevistadas reconheciam os riscos da infecção pelo HIV em seus bebês pela amamentação, mas não estavam plenamente convencidas de que outro tipo de leite poderia garantir, tanto quanto o leite materno, a saúde dos filhos; as mães (em especial aquelas cujos filhos adoeceram) se questionavam sobre ter seguido a orientação médica de não amamentar. Para esse autor, é preciso considerar o significado da impossibilidade de amamentar para mulheres HIV positivo, visto que, devido às inúmeras campanhas de incentivo ao aleitamento materno, as mulheres acreditam ser esse o melhor alimento, especialmente para uma criança que nasce em situação de grande vulnerabilidade, como na AIDS.

Os profissionais de saúde parecem deter o poder sobre o corpo destas mulheres, mas a posição do corpo se mostra, ora aceitando as intervenções, ora mantendo a lactação independente de medicamentos ou enfaixamentos.

As entrevistadas vivenciaram a não-amamentação em razão do HIV sentindo-se sem valor como mães, apresentaram dificuldades de aceitação tanto do diagnóstico para o HIV, quanto em relação à nãoamamentação.

O profissional deverá subsidiar a mulher de argumentos lógicos que lhe possibilite explicar para familiares e outras pessoas de sua comunidade ou de outro ciclo de sua relação, o fato de não estar amamentando, possibilitando-lhe assim, atender sua vontade de manter em sigilo seu estado sorológico. 27

A experiência de não amamentar, é, para as mulheres que participaram do presente estudo, penosa e emocionalmente desgastante.

Silva ${ }^{21}$ observou que as ações maternas em relação ao recém-nascido, incluindo a amamentação, são determinadas por uma visão pessoal da experiência e, que os profissionais de saúde deveriam levar em conta a avaliação e a compreensão das condições contextuais da nutriz quanto aos aspectos 
sociais, culturais e familiares, os quais influenciam a percepção e atribuição de significado do ato de amamentar.

A identidade da mulher se abala sob o signo da AIDS e não amamentar se torna um dos fatos concretos de estar doente. Além disso, os procedimentos para inibição da lactação, tão penosos, enfatizam para as mulheres/mães o dilema da nãoamamentação. ${ }^{21} \mathrm{~A}$ inibição com o enfaixamento traz para a mulher a confirmação de que não pode amamentar, como se fosse uma camisa de força para conte-la em seu híbrido biológico, cultural e humano. A motivação para continuar o tratamento e para não amamentar estará pautada na avaliação de riscos e benefícios para a própria mulher em relação a seu bebê e a si mesma.

Este estudo traz resultados restritos a uma área da região metropolitana de São Paulo, no qual as mulheres entrevistadas são de uma única unidade de saúde, portanto esses não podem ser generalizados. Contudo, os achados confirmam os resultados de outros trabalhos sobre o tema HIV e amamentação. 1,9,23,26

\section{Referências}

1. São Paulo (Estado). Secretaria de Saúde. Coordenação Estadual de DST/AIDS. Programa Estadual de DST/AIDS de São Paulo. Considerações sobre o aleitamento materno e o HIV. São Paulo; 2002.

2. São Paulo (Estado). Secretaria de Saúde. Coordenação Estadual de DST/AIDS. Programa Estadual de DST/AIDS de São Paulo. Alimentação para crianças nascidas de mães portadoras de HIV. São Paulo; 1999.

3. CDC (Centers for Disease Control) . Entry into prenatal care. United States: 1989-1997. MMWR. 2000; 49: 393-8.

4. Sibailly TS, Ekpini E, Boni-Ouattara E, Nkengasong J, Maurice C, Kouassi MK, Roels TH, Greenberg AE, Wiktor, SV. Clinical course of HIV infection and surveillance for zidovudine resistance among HIV-infected women receiving short-course zidovudine therapy in Abidjan. Côte d'Ivoire. In: Proceedings of the XIII International of AIDS Conference; 2000 July 9-14; South Africa. [Abstract TuPeC3354]. Available from: www.crt.saude.sp.gov.br/ down.Consensogestante2004.doc [2005 Oct 25].

5. Ministério da Saúde. Secretaria de Vigilância e Saúde. Programa Nacional de DST/AIDS. Recomendações para profilaxia da transmissão vertical do HIV e terapia antiretroviral em gestantes. Brasília (DF); 2004.

6. Rea MF. Reflexões sobre a amamentação no Brasil: de como passamos a 10 meses de duração. Cad Saúde Pública. 2003; 19 [Supl 1]: 37-45.

7. Silva IA. Psicologia, estresse e amamentação. In: Santos Junior LA, editor. A mama no ciclo gravídico-puerperal. São Paulo: Atheneu; 2000. p. 67

\section{Considerações Finais}

Os resultados mostram que as portadoras do HIV deparam-se com circunstâncias adversas que envolvem, além delas mesmas, um outro ser. A alimentação do bebê passa a ser mais um fator cujos riscos e benefícios devem ser medidos, além de lidar com cobranças e conflitos interiores relacionados à nãoamamentação. Esses aspectos devem ser considerados quando da elaboração de manuais sobre procedimentos de inibição da lactação.

Em relação ao acompanhamento de mulheres HIV positivo e seus filhos, a ampliação da humanização da assistência para o pós-parto e a ampliação da rede de atenção às mulheres pode facilitar o acesso aos serviços. Grupos de discussão sobre o HIV e a não-amamentação entre as portadoras do vírus, com coordenação inter e multidisciplinar são fundamentais para que essas mulheres possam lidar com os conflitos associados à não-amamentação.

8. Nakano AMS. As vivências da amamentação para um grupo de mulheres: nos limites de ser "o corpo para o filho" e ser "o corpo para si". Cad Saúde Pública. 2003; 19 [Supl 2]: S355-S63.

9. Knauth DR. Subjetividade feminina e soropositividade. In: Barbosa RM, Parker R, editores. Sexualidades pelo avesso: direitos, identidades e poder. São Paulo: IMS/UERJ; 1999. p.132

10. WHO (World Health Organization). World Health Assembly. Infant and young child nutrition. Geneva; 2001. (Resolution n.WHA 54.2).

11. Ministério da Saúde. Coordenação Nacional DST/AIDS. Secretaria Executiva. Coordenação-Geral da Política Nacional de Alimentação e Nutrição. Guia prático de preparo de alimentos para crianças menores de 12 meses verticalmente expostas ao HIV. Brasília (DF); 2003.

12. Martins J, Bicudo MAV. A pesquisa qualitativa em psicologia: fundamentos e recursos básicos. São Paulo: Moraes; 1994.

13. Muramatsu CH. Convivendo coma síndrome da tensão prémenstrual: um enfoque da fenomenologia existencial [tese doutorado]. São Paulo: Escola de Enfermagem da Universidade de São Paulo; 2001.

14. Schültz A. Fenomenologia del mundo social. Introdución a la sociologia compreensiva. Buenos Aires: Paidos; 1972.

15. Fustinoni SM. As necessidades de cuidado da parturiente: uma perspectiva compreensiva da ação social [tese doutorado]. São Paulo: Escola de Enfermagem da Universidade de São Paulo; 2000. 
16. Carvalho AS. Metodologia de entrevista: uma abordagem fenomenológica. Rio de Janeiro: AGIR; 1991.

17. Turato ER. Tratado de metodologia da pesquisa clínicoqualitativa: construção teórico-epistemológica, discussão comparada e aplicação nas áreas de saúde e humanas. Petrópolis: Vozes; 2003.

18. Bicudo MAV, Espósito VHC. Pesquisa qualitativa em educação. Piracicaba: Unimed; 1994.

19. Parker R. Na contramão da AIDS: sexualidade, intervenção, política. Rio de Janeiro: ABIA; 2002.

20. Ministério da Saúde. Secretaria Executiva. Coordenação Nacional de DST/AIDS. Políticas e diretrizes de prevenção das DST/AIDS entre mulheres. Brasília (DF); 2003.

21. Silva IA. Amamentar: uma questão de assumir riscos e benefícios. São Paulo: Robe; 1997.

22. Schültz A. El problema de la realidad social. Buenos Aires: Amorrortu; 1974.

23. São Paulo (Estado). Secretaria de Saúde. Coordenação Estadual de DST/AIDS. Programa Estadual de DST/AIDS. A gestação e o resultado indeterminado na pesquisa de anticorpos Anti-HIV. São Paulo; 2004.

Recebido em 10 de fevereiro de 2005

Versão final apresentada em 21 de março de 2006

Aprovado para publicação em 10 de abril de 2006
24. Santos EKA. A expressividade corporal do ser-mulher/mãe HIV positiva frente à privação do ato de amamentar: a compreensão do significado pela enfermeira à luz da teoria da expressão de Merleau-Ponty [tese doutorado]. Florianópolis: Programa de Pós-Graduação em Enfermagem, Centro Ciências da Saúde, Universidade Federal de Santa Catarina; 2004.

25. Ministério da Saúde. Secretaria Executiva. Coordenação Nacional de DST e AIDS. Projeto Nascer. Brasília (DF); 2003.

26. UNICEF (United Nations Children's Fund), UNAIDS (Aquared Joint United Nations Programme on HIV/AIDS), WHO (World Health Organization). Aconselhamento em HIV e alimentação infantil: um curso de treinamento: guia do treinador - 2000. São Paulo: Instituto de Saúde; 2003.

27. Ministério da Saúde. Secretaria de Vigilância e Saúde. Programa Nacional de DST/AIDS. Recomendações para profilaxia da transmissão vertical do HIV e terapia antiretroviral em gestantes. Brasília (DF); 2004. 1998. Inf Epidemiol SUS. 2001; 10: 113-20. 